\title{
Predicting wave dislodgment of mussels: variation in attachment strength with body size, habitat, and season
}

\author{
Heather L. Hunt*, Robert E. Scheibling \\ Department of Biology, Dalhousie University, Halifax, Nova Scotia B3H 4J1, Canada
}

\begin{abstract}
Breaking waves impose large hydrodynamic forces which may dislodge mussels and other organisms living on exposed rocky shores. We examined the effect of variation in attachment strength with size, habitat and season on the predicted probability of wave dislodgment of mussels Mytilus trossulus and $M$. edulis on an exposed shore on the Atlantic coast of Nova Scotia, Canada. Mussels on this shore are exposed to maximum significant wave heights of at least 7 to $9 \mathrm{~m}$ each winter and to maximal water velocities of at least $12 \mathrm{~m} \mathrm{~s}^{-1}$. We used Denny's (1995) mechanistic approach to predict probabilities of dislodgment from measures of attachment strength of mussels. Predicted probabilities of dislodgment indicated that mussels of 10 to $25 \mathrm{~mm}$ shell length are vulnerable to dislodgment by water velocities of $>7 \mathrm{~m} \mathrm{~s}^{-1}$. As a result of variation in dislodgment forces, probabilities of dislodgment did not differ consistently between tidepools and emergent rock, or with mussel size. Attachment strength increased from July to February as mussels were exposed to stronger wave action, reducing the probability of dislodgment by a given water velocity. This study indicates that knowledge of patterns of change in attachment strength are necessary for prediction of probabilities of dislodgment of mussels.
\end{abstract}

KEY WORDS: Disturbance $\cdot$ Wave forces $\cdot$ Mussels $\cdot$ Tide pools $\cdot$ Emergent rock $\cdot$ Seasonal variation $\cdot$ Mytilus

Resale or republication not permitted without written consent of the publisher

\section{INTRODUCTION}

Intertidal organisms on wave-exposed rocky shores experience large hydrodynamic forces due to breaking waves (Denny 1985, 1995, Denny \& Gaines 1990). This water motion has profound effects on many aspects of life on rocky shores, including the supply of food to suspension feeders and of nutrients to macroalgae, the delivery of larvae to the substratum, and the ability of mobile animals to forage for food. Large wave forces also break or dislodge individuals, resulting in mortality or redistribution to new sites. As a result, disturbance by wave-generated hydrodynamic forces is important in determining the structure and dynamics of communi-

*Present address: Institute of Marine and Coastal Sciences, 71 Dudley Rd. Rutgers University, New Brunswick, New Jersey 08901-8521, USA. E-mail: hunt@imcs.rutgers.edu ties on many wave-exposed shores (e.g. Dayton 1971, Menge 1976, Sousa 1979, Paine \& Levin 1981).

Mussels are abundant on rocky shores, and often are major occupiers of space in the intertidal zone (Seed \& Suchanek 1992). Dislodgment by waves is a major cause of loss of mussels in the intertidal zone (e.g. Paine \& Levin 1981) and the shallow subtidal zone (for mussels overgrown by algae, Witman 1987). Water movement exerts 3 types of forces on benthic organisms: lift, drag, and the acceleration reaction (Denny et al. 1985, Denny 1987, 1995). In a tightly packed mussel patch, mussels shield their neighbors from hydrodynamic forces acting along the direction of flow (drag and acceleration) and provide physical support in resisting these forces (Denny 1987). Furthermore, intertidal organisms such as mussels may not experience large accelerational forces because of the small spatial scale of surf-zone accelerations (Gaylord 2000). Lift forces, however, which are caused by a difference 
in pressure between the top and bottom of a mussel and act perpendicular to the direction of water motion, can potentially dislodge mussels (Denny 1987).

In addition to the hydrodynamic forces it experiences, a mussel's risk of dislodgment varies with its strength of attachment to the substratum. Attachment strength of mussels depends on the number of byssal threads anchoring them to the substratum (Bell \& Gosline 1997). These threads decay and must be replaced to maintain a constant attachment strength, which can be metabolically costly (Hawkins \& Bayne 1985). Mussels respond to their flow environment by altering their attachment strength. In the laboratory, water agitation increases the number of byssal threads produced (Young 1985). In the field, attachment strength varies with location in a mussel bed (Witman \& Suchanek 1984, Bell \& Gosline 1997), wave exposure of the site (Witman \& Suchanek 1984), and, seasonally with wind conditions (Price 1982). Because the attachment strength of mussels can vary seasonally, temporal variation in attachment strength must be incorporated in any assessment of dislodgment risk of mussels (Denny 1995).

Predicting the dynamics of communities on waveexposed shores requires consideration of losses due to wave dislodgment. Denny (1995) developed a mechanistic approach for calculating the probability of wave dislodgment of an organism. In this study, we use Denny's method to examine the effect of seasonal variation in water velocity and attachment strength on the probabilities of wave dislodgment of mussels (predominantly Mytilus trossulus, with some $M$. edulis and hybrids of the 2 species) of different sizes in tidepools and on emergent rock on a wave-exposed shore in Nova Scotia, Canada. Tidepools, apart from serving as a refuge from many of the stressful environmental conditions on emergent rock during low tide (Metaxas \& Scheibling 1993), may provide some protection from wave forces because the overlying water column reduces the maximal horizontal water velocity experienced by benthic organisms (Denny 1995).

\section{METHODS}

This study was conducted on an exposed rocky shore at Cranberry Cove $\left(44^{\circ} 28^{\prime} \mathrm{N}, 63^{\circ} 56^{\prime} \mathrm{W}\right)$ near Halifax, Nova Scotia, Canada. The shore is composed of granite platforms and outcrops with occasional large boulders (glacial erratics). There are numerous tidepools in irregular depressions along the shore, ranging from a few decimeters to over $10 \mathrm{~m}$ in maximum dimension. The shore is exposed to large southerly swells in fall and winter. We obtained records of significant wave heights (average height of the largest one third of all waves measured) for July 1994 to March 1998 from a buoy at the mouth of Halifax Harbour $\left(44.483^{\circ} \mathrm{N}\right.$, $63.417^{\circ} \mathrm{W}$, depth $\left.56.7 \mathrm{~m}\right) \sim 40 \mathrm{~km}$ from the study site (Department of Fisheries and Oceans, Canada, unpubl. data). We measured maximum wave forces in tidepools and on emergent rock from November 1994 to April 1995 using wave meters based on the design of Bell \& Denny (1994). Each meter consists of a practice golf ball attached to a spring in a plastic housing which is anchored to the substratum. The extension of the spring was converted to water velocity (Bell \& Denny 1994). Three wave meters were deployed continuously in each habitat, and were checked and reset at 10 to 43 d intervals.

We measured the attachment strength of individual mussels Mytilus spp., at or near the edge of patches, as the force required to dislodge them from the substratum. In July, August, and November 1997, and February 1998, we measured dislodgment forces for 7 to 10 mussels from each of 2 (November), 3 (August, February), or 6 (July) tidepools and plots of emergent rock. Dislodgment force was measured perpendicular to the substratum because mussels are most strongly affected by hydrodynamic forces acting in this direction (Denny 1987). A thin multifilament fishing line was tied around each mussel and attached to a 250 or $2000 \mathrm{~g}$ spring scale (Ohaus). The dislodgment force was measured on the scale by pulling it at a right angle to the substratum until the mussel was detached. The shell length (SL, mm) of each detached mussel was measured and converted to cross-sectional, planform area $\left(A, \mathrm{~cm}^{2}\right)$ using the relationship: $A=0.003 \times \mathrm{SL}^{1.833}$ (Hunt $\&$ Scheibling 1998), which approximates the cross-sectional area as an ellipse, with shell height and width as the axes. We were not able to measure dislodgment force for mussels in the center of patches, or for individuals $<5 \mathrm{~mm} \mathrm{SL}$, because of difficulties in tying the line around these individuals. Because the dislodgment force of mussels in the center of patches is generally lower than that of individuals at the edge (Witman \& Suchanek 1984), our measurements may overestimate the average dislodgment force of mussels in patches.

To examine the importance of wave dislodgment as a cause of loss and redistribution of mussels, we used Denny's (1995) method to calculate probabilities of wave dislodgment using the measured dislodgment forces and estimates of hydrodynamic forces imposed on mussels. Firstly, the data relating dislodgment force $(f)$ to $A$ were fit to an allometric model: $f_{\mathrm{p}}=j+m A^{q}$, where $f_{\mathrm{p}}$ is the predicted dislodgment force and $j, m$, and $q$ are constants fit to the power curve for each date using a nonlinear, simplex iterative procedure (SYSTAT: Wilkinson 1992). If the intercept $j$ was negative, we fit a new curve with zero $y$ intercept. To obtain relative dislodgment forces, each measured force was normalized by dividing it by the dislodgment force predicted by 
the allometric model. The variation in normalized dislodgment forces allows the estimation of the probability that a randomly selected mussel will have an attachment strength exceeding a given value. The normalized dislodgment forces $\left(f_{\mathrm{n}}=f / f_{\mathrm{p}}\right)$ were ranked in ascending order and the probability $(p)$ that an individual had a normalized dislodgment force less than a force of rank $i$ was estimated as: $p\left(f_{n} \leq f_{n, i}\right)=i /(n+1)$, where $n$ is the total number of individuals sampled. A mathematical description of the cumulative probability distribution of normalized dislodgment force $\left(\mathrm{p}\left[f_{\mathrm{n}}\right]\right)$ was then obtained by fitting a modified Weibull model: $\mathrm{p}\left(f_{\mathrm{n}}\right)=\exp \left\{-\left[\left(a-b f_{f \mathrm{n}}\right) /(a-b c)\right]^{1 / b}\right\}$, where $a, b$, and $c$ are constants (Table 1). The Weibull model provided a good estimate of the cumulative probability distribution of the normalized dislodgment forces for each sampling date $\left(\mathrm{r}^{2}>0.99\right.$, Table 1$)$.

We then predicted the hydrodynamic lift force imposed on mussels based on the relationship between lift $(L)$ and maximal water velocity

$$
(U): L=\left(1 / 2 \rho U^{2}\right) C_{1} A
$$

where $\rho$ is the density of seawater $\left(1025 \mathrm{~kg} \mathrm{~m}^{-3}\right), C_{1}$ is the coefficient of lift, and $A$ is the cross-sectional area of a mussel (Denny 1987). Denny (1987) estimated that $C_{1}$ for Mytilus californianus is 0.88 . Because the relationship between shell height, length, and width of $M$. trossulus is similar to that of $M$. californianus, 0.88 is also a reasonable estimate of the lift coefficient for $M$. trossulus (Bell \& Gosline 1997). Using this equation, we

Table 1. Modified Weibull model of the cumulative probability distribution of normalized wave forces: $\mathrm{p}\left(f_{\mathrm{n}}\right)=\exp \left\{-\left[\left(a-b f_{\mathrm{fn}}\right) /\right.\right.$ $(a-b c)]^{1 / b}$. Values for $a, b, c$ are constants fit to the model. Models were fit to the data using a nonlinear, simplex iterative procedure (SYSTAT: Wilkinson 1992). Sample size $=60$ mussels per habitat in July, 30 per habitat in August and February, and 14 in tide-pools and 17 on emergent rock in November

\begin{tabular}{|lrrrr|}
\hline Habitat & \multicolumn{5}{c|}{$\begin{array}{c}\text { Constants from cumulative } \\
\text { probability distribution }\end{array}$} \\
& $a$ & $b$ & $c$ & $\mathrm{r}^{2}$ \\
\hline July & & & & \\
$\quad$ Tidepool & 0.19 & -0.31 & 0.67 & 0.999 \\
$\quad$ Emergent Rock & 0.29 & -0.14 & 0.74 & 0.999 \\
August & & & & \\
$\quad$ Tidepool & 0.71 & 0.31 & 0.81 & 0.996 \\
$\quad$ Emergent Rock & 0.20 & -0.16 & 0.79 & 0.998 \\
November & & & & \\
$\quad$ Tidepool & 0.50 & -0.17 & 0.63 & 0.991 \\
$\quad$ Emergent Rock & -0.07 & -0.49 & 0.74 & 0.992 \\
February & & & & \\
$\quad$ Tidepool & 0.48 & 0.08 & 0.73 & 0.999 \\
Emergent Rock & 0.34 & -0.02 & 0.80 & 0.995 \\
\hline
\end{tabular}

calculated lift forces imposed on mussels of 4 sizes (10, 15,20 , and $25 \mathrm{~mm} \mathrm{SL}$, which correspond to cross-sectional areas of $0.20,0.43,0.73$, and $1.1 \mathrm{~cm}^{2}$ respectively) over a range of water velocities. Very few mussels at Cranberry Cove exceed $20 \mathrm{~mm}$ SL (Hunt \& Scheibling 1995, 1998). We did not calculate probabilities of dislodgment for mussels $\leq 5 \mathrm{~mm}$ because we did not have measurements of dislodgment forces for them. To estimate the probability of dislodgment of mussels of each size by water velocities of up to $15 \mathrm{~m}$ $\mathrm{s}^{-1}$, we normalized the calculated lift force for each mussel size by dividing it by $f_{\mathrm{p}}$ for a mussel of that size, and used this as $f_{n}$ in the Weibull model to obtain the probability of dislodgment.

\section{RESULTS}

Significant wave heights recorded at a nearshore buoy were highest in fall and winter storms, reaching $9.4 \mathrm{~m}$ in February 1995, $7.0 \mathrm{~m}$ in December 1995, $8.7 \mathrm{~m}$ in September 1996, and $8.2 \mathrm{~m}$ in February 1998 (Fig. 1). Maximum wave-force meters deployed during winter 1994/95 recorded water velocities up to $12 \mathrm{~m} \mathrm{~s}^{-1}$ (Fig. 2). Maximum water velocities were greater on emergent rock than in tidepools $\left(F_{1,12}=5.9, \mathrm{p}=0.032\right)$ and differed among dates $\left(F_{4,12}=15.4, \mathrm{p}=<0.001\right)$; there was no interaction between habitat and date $\left(F_{4,12}=0.6, \mathrm{p}=0.69\right)$.

The force required to dislodge mussels Mytilus spp. ranged from 0.5 to $18 \mathrm{~N}$, increasing with increasing mussel size (Fig. 3). ANCOVA showed that the relationship between dislodgment force and shell cross-sectional area differed between habitats and among months (Table 2). Therefore, we fitted the data to the allometric model separately for each habitat for each month. The relationship between dislodgment force and shell area

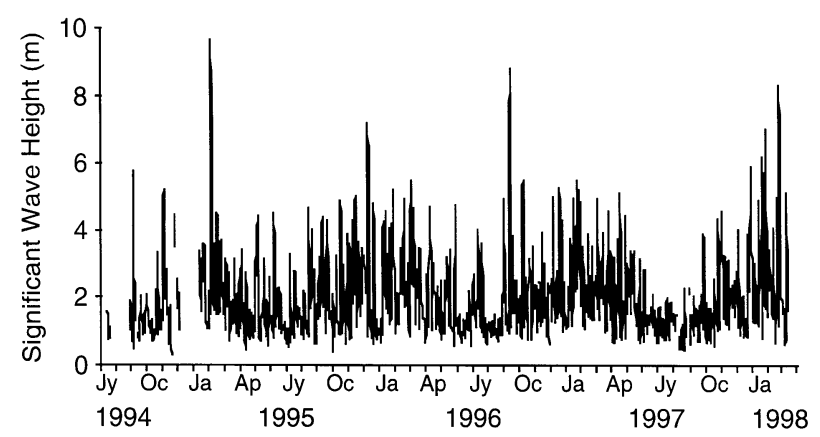

Fig. 1. Maximum daily significant wave heights (average height of the largest one-third of all waves measured) for July 1994 to March 1998 from a buoy at the mouth of Halifax Harbour $\left(44.483^{\circ} \mathrm{N}, 63.417^{\circ} \mathrm{W}\right.$; depth $\left.56.7 \mathrm{~m}\right) \sim 40 \mathrm{~km}$ from the study site 


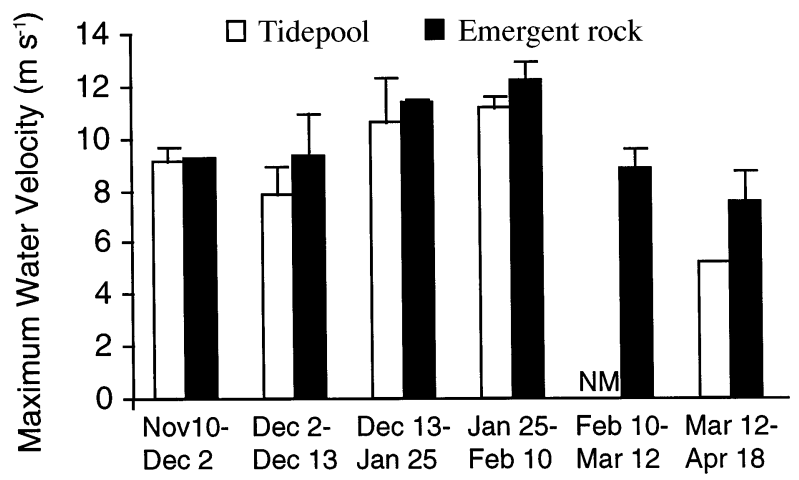

Fig. 2. Mean $(+1 \mathrm{SD})$ maximum water velocities $\left(\mathrm{m} \mathrm{s}^{-1}\right)$ in tidepools and on emergent rock (averaged across 1 to 3 wave meters per habitat) at Cranberry Cove between November 1994 and April 1995. No measurements were taken in tidepools during the period February 10 to March 12

was exponential, with an exponent ranging from 0.53 to 3.51. Predicted dislodgment forces were lower in tidepools than on emergent rock for small mussels (ca 0.2 to $\leq 0.6 \mathrm{~cm}^{2}$ shell area) but greater in tidepools than on emergent rock for the largest mussels. In tidepools, predicted dislodgment forces of mid-size mussels increased over time, while those of the smallest mussels remained

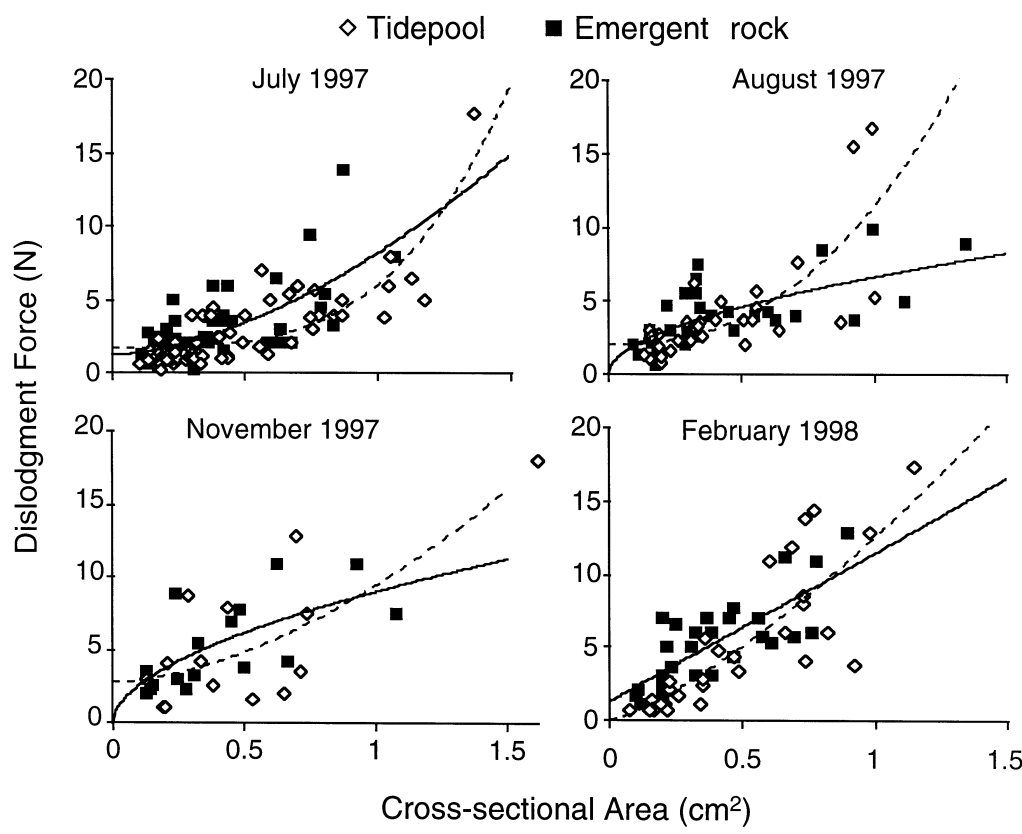

Fig. 3. Mytilus. Relationship between force (N) required to dislodge a mussel and mussel cross-sectional area $\left(\mathrm{cm}^{2}\right)$ in tidepools and on emergent rock in July $(\mathrm{n}=60$ per habitat), August $(\mathrm{n}=30)$, and November $(\mathrm{n}=14$ in tidepools, $\mathrm{n}=17$ on emergent rock) 1997, and February $1998(\mathrm{n}=30)$. Lines (dashed = tidepools; continuous $=$ emergent rock) indicate dislodgment force predicted by the allometric model $\left(\mathrm{r}^{2}=0.85\right.$ and 0.78 on tidepools and in emergent rock respectively in July; $r^{2}=0.81$ and 0.88 respectively in August; 0.83 and 0.87 respectively in November; 0.86 and 0.91 respectively in February) (N) of mussels. Factors are habitat (tidepools and emergent covariate is shell area $\left(\mathrm{cm}^{2}\right)$. Sample size $=30$ mussels per habi(data from extra tidepools and plots excluded for alance), August and February, and 14 in tidepools and 17 on emergent rock in November. ${ }^{*} \mathrm{p}<0.05{ }_{i}{ }^{* *} \mathrm{p}<0.01 i^{* * *} \mathrm{p}<0.001$

\begin{tabular}{|lrccc|}
\hline Source & df & MS & \multicolumn{1}{c|}{$F$} & $\mathrm{p}$ \\
\hline Habitat & 1 & 0.44 & 17.0 & $0.001^{* *}$ \\
Month & 3 & 0.13 & 5.0 & $0.002^{* *}$ \\
Shell area & 1 & 6.17 & $<0.001$ & $<0.001^{* * *}$ \\
Habitat $\times$ Month & 3 & 0.03 & 1.1 & 0.35 \\
Habitat $\times$ Shell area & 1 & 0.11 & 4.2 & $0.04^{*}$ \\
Month $\times$ Shell area & 3 & 0.11 & 4.3 & $0.01^{*}$ \\
Habitat $\times$ Month $\times$ Shell area & 3 & 0.02 & 0.8 & 0.51 \\
Residual & 195 & 0.03 & & \\
\hline
\end{tabular}

relatively constant. On emergent rock, predicted dislodgment forces of mid-size mussels were similar in July and August, but greater in November and February than in the summer. These changes in dislodgment force (attachment strength of mussels) between sampling dates may have been a response to increased wave action between the measurement dates (Fig. 1). The maximum significant wave heights recorded at a wave buoy in the month preceding the July measurement and between the July and August measurements were $<2 \mathrm{~m}$, although higher waves were observed for at least $1 \mathrm{~d}$ in August when the wave buoy was disabled by a storm (T. Balch, Dalhousie University, pers. comm.). The maximum significant wave heights in the month preceding the November measurement were $>2 \mathrm{~m}$ on $19 \mathrm{~d}$ and $>4 \mathrm{~m}$ on $2 \mathrm{~d}$, while those preceding the February measurement were $>2 \mathrm{~m}$ on $20 \mathrm{~d}$ and $>4 \mathrm{~m}$ on $6 \mathrm{~d}$.

Predicted lift forces increased with increasing water velocity and mussel size (Fig. 4). For example, lift forces on 10 and $25 \mathrm{~mm}$ mussels were 0.3 and $1.8 \mathrm{~N}$ respectively at $6 \mathrm{~m} \mathrm{~s}^{-1}$, and 2.1 and $11.1 \mathrm{~N}$ at $15 \mathrm{~m} \mathrm{~s}^{-1}$. On average, velocities in tidepools were $87 \%$ of those on emergent rock (Fig. 2). Therefore, although lift forces in the 2 habitats are identical at a given velocity, they are lower in tidepools than on emergent rock at a given time, as indicated by the double $x$-axes in Figs. $4 \& 5$. Because of increasing lift forces, probabilities of dislodgment also increased with increasing water 
velocity (Fig. 5). Probabilities of dislodgment at a given water velocity generally were greater in tidepools than on emergent rock, except in August when larger mussels (20 and $25 \mathrm{~mm}$ ) were more likely be dislodged on emergent rock than in tidepools at velocities $>10 \mathrm{~m} \mathrm{~s}^{-1}$ (Fig. 5). Incorporating the between-habitat difference in water velocity reduced the differences in probabilities of dislodgment at a given time between tidepools and emergent rock. Thus, probabilities of dislodgment were predicted to be greater in tidepools than on emergent rock in about half of the cases, but greater on emergent rock or similar between habitats in the others.

Predicted probabilities of dislodgment suggest that mussels 10 to $25 \mathrm{~mm}$ SL are vulnerable to dislodgment by water velocities of $>7 \mathrm{~m} \mathrm{~s}^{-1}$ (Fig. 5). For the attachment strengths we recorded, we would predict that maximal water velocities of $6 \mathrm{~m} \mathrm{~s}^{-1}\left(5.2 \mathrm{~m} \mathrm{~s}^{-1}\right.$ in tidepools) would dislodge $<9 \%$ of mussels in either habitat in any of the 4 mo sampled. By comparison, maximal water velocities of $9 \mathrm{~m} \mathrm{~s}^{-1}$ on emergent rock $\left(7.8 \mathrm{~m} \mathrm{~s}^{-1}\right.$ in tidepools) were predicted to dislodge 10 to $15 \%$ of large (20 to $25 \mathrm{~mm} \mathrm{SL}$ ) mussels on emergent rock and 12 to $35 \%$ in tidepools in July, but only 2 to $5 \%$ in February. Maximal water velocities of $12 \mathrm{~m} \mathrm{~s}^{-1}\left(10.4 \mathrm{~m} \mathrm{~s}^{-1}\right.$ in tidepools) were predicted to dislodge 40 to $51 \%$ and 41 to $70 \%$ of large mussels on emergent rock and in tidepools respectively in July, and 11 to $15 \%$ of large mussels in February. Measurements of maximal water velocities at Cranberry Cove in 1995 (Fig. 2) can be

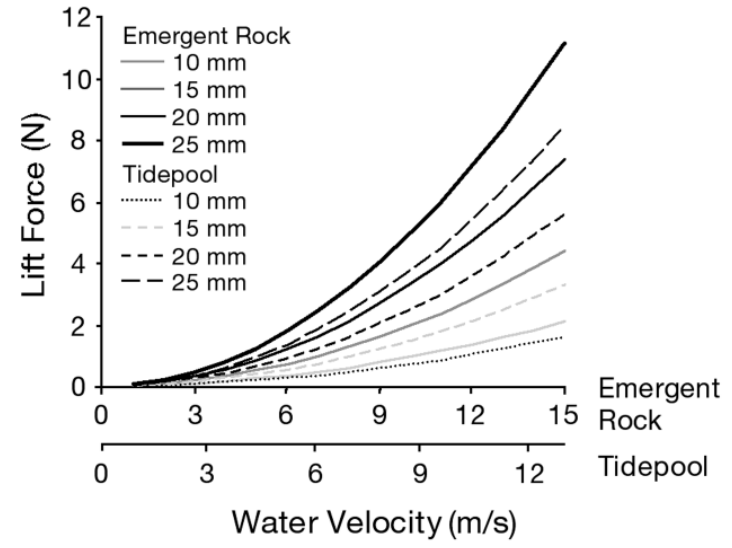

Fig. 4. Mytilus. Relationship between the hydrodynamic force imposed on a mussel (lift) and maximal water velocity for mussels of 10, 15, 20, and $25 \mathrm{~mm} \mathrm{SL}$. The different scales for water velocity indicate that, at a given time, water velocities in tidepools are $87 \%$ of those on emergent rock

used to examine the wave conditions (Fig. 1) under which different probabilities of dislodgment are predicted.

The relationship between mussel size and probability of dislodgment, which depends on the relationships between dislodgment force and size, and between lift force and size, varied with habitat and date (Fig. 6). Probability of dislodgment increased with increasing mussel size on emergent rock in August, November (only at velocities $\geq 10 \mathrm{~m} \mathrm{~s}^{-1}$ ), and February, but decreased with mussel size in tidepools in February.

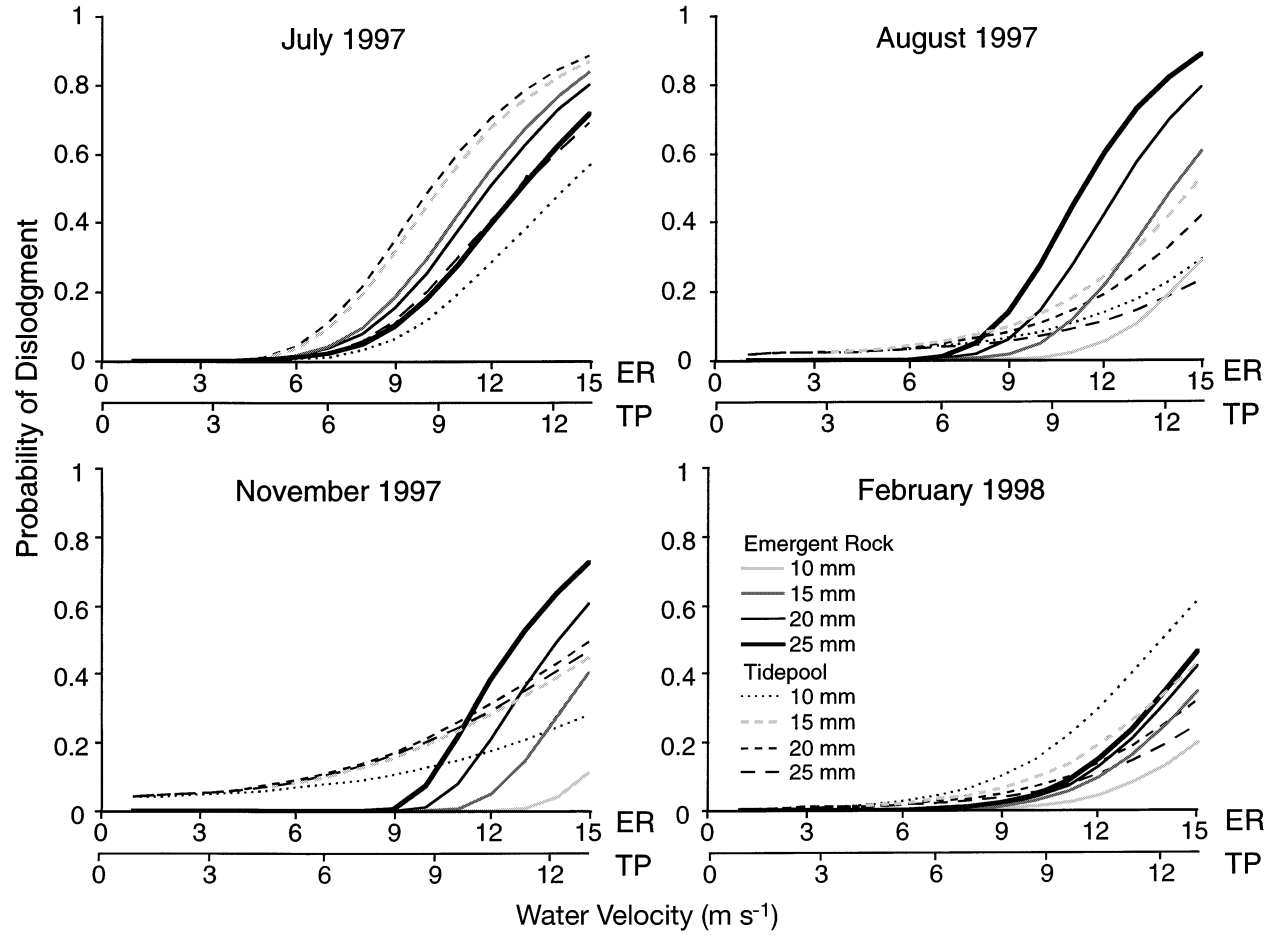

Fig. 5. Mytilus. Relationship between probability of dislodgment and water velocity in July, August, and November 1997 and February 1998 for mussels of $10,15,20$, and $25 \mathrm{~mm} \mathrm{SL}$ in tidepools (TP) and on emergent rock (ER). The different scales for water velocity indicate that, at a given time, water velocities in tidepools are $87 \%$ of those on emergent rock 


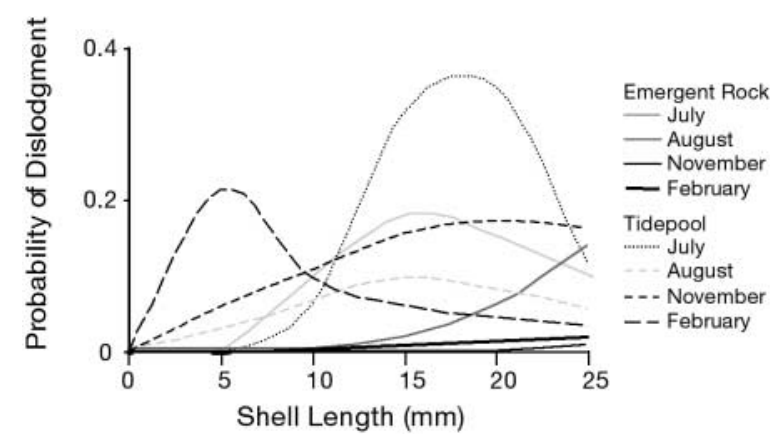

Fig. 6. Relationship between probability of dislodgment and shell length (mm) in July, August, and November 1997 and February 1998 at a water velocity of $7.8 \mathrm{~m} \mathrm{~s}^{-1}$ in tidepools and $9 \mathrm{~m} \mathrm{~s}^{-1}$ on emergent rock

Probability of dislodgment was greatest for 15 and $20 \mathrm{~mm}$ SL mussels in both habitats in July and in tidepools in August. In tidepools in November, probability of dislodgment was similar for 15, 20, and $25 \mathrm{~mm}$ mussels and lower for $\leq 10 \mathrm{~mm}$ mussels.

Changes in the probability of dislodgment of mussels between measurement dates differed between habitats (Fig. 5). For example, probabilities of dislodgment of $20 \mathrm{~mm}$ SL mussels by water velocities $>5 \mathrm{~m} \mathrm{~s}^{-1}$ were 2 to 5 times greater in July than in August 1997 in tidepools, but similar between these months on emergent rock. Probabilities of dislodgment of these mussels were greater in August than in November on emergent rock, but similar between these months in tidepools. Probability of dislodgment of all size classes of mussels was lowest in February, except for $10 \mathrm{~mm}$ mussels in tidepools.

\section{DISCUSSION}

Mytilus spp. living on wave-exposed shores such as Cranberry Cove are subjected to large wave forces, particularly during fall and winter storms. Our predictions of probabilities of wave dislodgment of mussels at Cranberry Cove suggest that individuals $\geq 10 \mathrm{~mm}$ SL are vulnerable to dislodgment by water velocities $\geq 7 \mathrm{~m} \mathrm{~s}^{-1}$. We have recorded velocities of this magnitude when significant wave heights were $>4 \mathrm{~m}$. Waves of this size are a regular occurrence in nearshore waters along this coast (Fig. 1). During a storm with maximum significant wave heights of $9.4 \mathrm{~m}$ in February 1995 (Fig. 1), we recorded water velocities at Cranberry Cove of up to $12 \mathrm{~m} \mathrm{~s}^{-1}$, capable of dislodging a sizable proportion of individuals (Fig. 5). The importance of wave dislodgment as a cause of loss of mussels at this site is supported by other studies. We found that a high proportion (43 to $100 \%$ ) of decreases in area of experimental mussel patches over a 15 mo period were not accounted for by in situ mor- tality (as indicated by empty shells) (Hunt \& Scheibling 2001). Also, while monitoring tagged mussels (ca 10 to $15 \mathrm{~mm} \mathrm{SL}$ ) over 3 wk periods, we recorded losses (excluding in situ mortality) consistent with our calculated probabilities of dislodgment: $8 \%$ on emergent rock and $16 \%$ in tidepools on average in July/ August $1994 / 95$, and $42 \%$ on emergent rock and $17 \%$ in tidepools in October 1995 when wave heights were greater (Hunt 1997).

Wave dislodgment is an important cause of loss of mussels on many other wave-exposed shores, both in the intertidal (e.g. Harger \& Landenberger 1971, Paine \& Levin 1981) and the subtidal (Witman \& Suchanek 1984, Witman 1987) zone. On Tatoosh Island, Washington, Denny (1995) calculated that Mytilus californianus experiences wave-induced stresses close to its modal dislodgment force. At Cranberry Cove, water velocities of $15 \mathrm{~m} \mathrm{~s}^{-1}$ generate lift forces equal to the modal dislodgment force of the mussels measured in February. Mussels at Cranberry Cove may not experience such velocities every year, but we expect that velocities of $15 \mathrm{~m} \mathrm{~s}^{-1}$ occur during the largest storms. Wave forces measured at Cranberry Cove during the winter of 1995 were comparable to those recorded by Blanchette (1997), with the same type of maximum wave force recorder, at an exposed shore in Oregon. The yearly average significant wave height at Cranberry Cove from 1995 to 1997 was 1.47 m, lower than the average (1.9 to $2.5 \mathrm{~m}$ ) recorded at a number of sites along the west coast of North America (Denny 1995). However, M. trossulus and $M$. edulis have a much weaker byssal attachment (per unit cross-sectional area) than M. californianus (Harger 1970, Witman \& Suchanek 1984, Bell \& Gosline 1997), the dominant mussel on the west coast.

To understand how dislodgment by waves is influenced by mussel size, habitat, and season, we need to examine how these factors affect hydrodynamic forces and attachment strength. The hydrodynamic forces experienced by mussels increase with increasing mussel size (Denny 1987), and depend on whether an individual is solitary or in a patch (Bell \& Gosline 1997), and on its position within a patch (Witman \& Suchanek 1984). The force required to dislodge a mussel depends on the number of anchoring byssal threads (Bell \& Gosline 1997). In our study and others (Harger 1970, Witman \& Suchanek 1984), attachment strength increased with increasing mussel size. However, lift forces often increased faster with size than did attachment strength, resulting in a greater probability of dislodgment for larger mussels than smaller ones. The relationship between probability of dislodgment and mussel size varied with habitat and season. In contrast, Denny (1995) found that the attachment strength of Mytilus californianus increased faster than the area 
exposed to flow, resulting in large mussels being somewhat less susceptible to disturbance than small mussels. Bell \& Gosline (1997) found that tenacity (dislodgment force/unit area) of $M$. californianus and $M$. trossulus was relatively constant with mussel size for individuals of 15 to $50 \mathrm{~mm} \mathrm{SL}$.

Because mussels in a patch are tightly bound together by their byssal threads, an individual mussel's probability of dislodgment will be influenced by its neighbours, particularly for very small mussels. Dislodgment by waves of 1 or a few mussels in a patch would render the remaining mussels more vulnerable to hydrodynamic forces acting parallel to the substratum, drag and the acceleration reaction, and could lead to the dislodgment of many other mussels in the patch (Denny 1987). Wave action also may interact with other causes of mortality. For example, in an experiment examining whelk predation (Hunt \& Scheibling 1998), predation could not entirely account for the decrease in mussel cover and abundance which occurred in unmanipulated plots. We attributed this discrepancy to wave action, as dislodgment of the shells of mussels eaten by predators would remove recruits associated with the drilled shells and weaken the surrounding mussel matrix.

We found seasonal variations in dislodgment forces and, therefore, in probabilities of dislodgment of mussels by a given water velocity. Similarly, Price (1980) found a seasonal cycle of attachment strength of Mytilus edulis in South Wales, UK, with a maximum in September and a minimum in May. Increases in the average attachment strength of a mussel population could result from the dislodgment of the most weakly attached individuals as well as from increases in the number of byssal threads produced. However, dislodgment of weakly attached individuals would result in a substantial shift in mean tenacity only if a large fraction of individuals were dislodged (Denny 1995). Price (1982) found that attachment strength decreased after 1 mo of weak wave action, which could only result from a decrease in the number of byssal threads. Seasonal variation in attachment strength may counteract seasonal changes in wave action to dampen any seasonality in the probability of wave dislodgment. For example, we estimate that $<2 \%$ of $20 \mathrm{~mm}$ mussels on emergent rock in August $(<6 \%$ in tidepools) were dislodged during the storm on September 29, 1997, when the significant wave height reached $3.9 \mathrm{~m}$, and $<7 \%$ of those on emergent rock in February $(<10 \%$ in tidepools) were dislodged during the storm on February 25,1998 , when the significant wave height reached $8.2 \mathrm{~m}$ (Figs. 1 \& 5).

Between-habitat differences in the probability of dislodgment of mussels at our site varied over time as a result of variations in dislodgment forces. Therefore, although wave forces were higher on emergent rock than in tidepools, probability of dislodgment did not necessarily mirror this pattern. We do not understand the factors influencing variation in the attachment strength of mussels well enough to be able to explain this temporal variation in between-habitat differences.

This type of mechanistic approach to prediction of probabilities of wave dislodgment (from Denny 1995) is powerful because it allows prediction of rates of disturbance. However, for organisms like mussels, whose dislodgment force is not constant, variation in attachment strength can affect relative probabilities of dislodgment between times, habitats, and sizes of individuals. Probability of dislodgment cannot be predicted from knowledge of hydrodynamic forces alone. We still have much to learn about the factors that control attachment strength. The mechanisms and response time of varying attachment strength in accordance with seasonal changes in wave action require further investigation.

Acknowledgements. Bruce Bradshaw and Tracey DoughertyPoupore at the Marine Environmental Data Services Branch of Fisheries and Oceans in Ottawa, Canada, provided data on significant wave heights. H.L.H. was supported by a Natural Science and Engineering Research Council (NSERC) Postgraduate Award and an Izaak Walton Killam Memorial Scholarship from Dalhousie University and the research was supported by an NSERC Research Grant to R.E.S.

\section{LITERATURE CITED}

Bell EC, Denny MW (1994) Quantifying 'wave exposure': a simple device for recording maximum velocity and results of its use at several field sites. J Exp Mar Biol Ecol 181: 9-29

Bell EC, Gosline JM (1997) Strategies for life in flow: tenacity, morphometry, and probability of dislodgment of two $\mathrm{My}$ tilus species. Mar Ecol Prog Ser 159:197-208

Blanchette CA (1997) Size and survival of intertidal plants in response to wave action: a case study with Fucus gardneri. Ecology 78:1563-1578

Dayton PK (1971) Competition, disturbance, and community organization: the provision and subsequent utilization of space in a rocky intertidal community. Ecol Monogr 41: 351-389

Denny MW (1985) Wave forces on intertidal organisms: a case study. Limnol Oceanogr 30:1171-1187

Denny MW (1987) Lift as a mechanism of patch initiation in mussel beds. J Exp Mar Biol Ecol 113:231-245

Denny MW (1995) Predicting physical disturbance: mechanistic approaches to the study of survivorship on wave-swept shores. Ecol Monogr 65:371-418

Denny MW, Gaines SD (1990) On the prediction of maximal intertidal wave forces. Limnol Oceanogr 35:1-15

Denny MW, Daniel TH, Koehl MAR (1985) Mechanical limits to size in wave-swept organisms. Ecol Monogr 55:69-102

Gaylord B (2000) Biological implications of surf-zone flow complexity. Limnol Oceanogr 45:174-188

Harger JRE (1970) The effect of wave impact on some aspects 
of the biology of sea mussels. Veliger 12:401-414

Harger JRE, Landenberger DE (1971) The effect of storms as a density dependent mortality factor on populations of sea mussels. Veliger 14:195-201

Hawkins AJS, Bayne BL (1985) Seasonal variation in the relative utilization of carbon and nitrogen by the mussel Mytilus edulis: budgets, conversion efficiencies and maintenance requirements. Mar Ecol Prog Ser 25:181-188

Hunt HL (1997) Structure and dynamics of intertidal mussel (Mytilus trossulus, M. edulis) assemblages. $\mathrm{PhD}$ thesis, Dalhousie University, Halifax

Hunt HL, Scheibling RE (1995) Structure and dynamics of mussel patches in tidepools on a rocky shore in Nova Scotia, Canada. Mar Ecol Prog Ser 124:105-115

Hunt HL, Scheibling RE (1998) Effects of whelk (Nucella lapillus [L.]) predation on mussel (Mytilus trossulus [Gould], M. edulis [L.]) assemblages in tidepools and on emergent rock on a wave-exposed rocky shore in Nova Scotia, Canada. J Exp Mar Biol Ecol 226:87-113

Hunt HL, Scheibling RE (2001) Patch dynamics of mussels on rocky shores: integrating process to understand pattern. Ecology (in press)

Menge BA (1976) Organization of the New England rocky intertidal community: role of predation, competition, and environmental heterogeneity. Ecol Monogr 46:355-393

Metaxas A, Scheibling RE (1993) Community structure and

Editorial responsibility: Roger Hughes (Contributing Editor), Bangor, Wales, UK organization of tidepools. Mar Ecol Prog Ser 98:187-198

Paine RT, Levin SA (1981) Intertidal landscapes: disturbance and the dynamics of pattern. Ecol Monogr 51:145-178

Price HA (1980) Seasonal variation in the strength of byssal attachment of the common mussel Mytilus edulis L. J Mar Biol Assoc UK 60:1035-1037

Price HA (1982) An analysis of factors determining seasonal variation in the byssal attachment strength of Mytilus edulis. J Mar Biol Assoc UK 62:147-155

Seed R, Suchanek TH (1992) Population and community ecology of Mytilus. In: Gosling E (ed) The mussel Mytilus: ecology, physiology, genetics, and culture. Elsevier, New York, p 87-169

Sousa WP (1979) Disturbance in marine intertidal boulder fields: the nonequilibrium maintenance of species diversity. Ecology 60:1225-1239

Wilkinson L (1992) SYSTAT: the system for statistics, 2nd edn. SYSTAT Inc., Evanston, IL

Witman JD (1987) Subtidal coexistence: storms, grazing, mutualism, and the zonation of kelps and mussels. Ecol Monogr 57:167-187

Witman JD, Suchanek TH (1984) Mussels in flow: drag and dislodgement by epizoans. Mar Ecol Prog Ser 16:259-268

Young GA (1985) Byssus-thread formation by the mussel Mytilus edulis: effects of environmental factors. Mar Ecol Prog Ser 24:261-271

Submitted: January 25, 2000; Accepted: July 4, 2000 Proofs received from author(s): March 13, 2001 